Brain folate

cystathionase homocyst(e)ine

cyst(e)ine methyltransferase

fetus

\title{
Development of Methyltransferase Activities of Human Fetal Tissues
}

\author{
GERALD E. GAULIJ ${ }^{301}$, WOLF VON BERG, NIELS G. R. RÄIHÄ, \\ AND JOHN A. STURMAN
}

From the Department of Pediatric Research, New York State Institute for Research in Mental Retardation, Staten Island, New York, and the Department of Pediatrics and Clinical Genetics Center, Mount Sinai School of Medicine of the City University of New York, New York, New York, USA, and Department of Pediatrics and Medical Chemistry, University of Helsinki, Helsinki, Finland

\section{Extract}

$\mathrm{JV}^{5}$-Methyltetrahydrofolate-homocysteine methyltransferase specific activity was higher in fetal (2nd trimester) human liver and kidney $(4.70 \pm 0.20$ and $7.25 \pm 0.23$ $\mathrm{nmol} / \mathrm{mg}$ protein $/ \mathrm{hr})$ than in mature human liver and kidney $(1.30 \pm 0.16$ and 0.76 $\pm 0.18 \mathrm{nmol} / \mathrm{mg}$ protein $/ \mathrm{hr}$ ). During the same period, there was a significant correlation of decreasing specific activity of this enzyme in fetal brain with increasing crownrump length $(r=-0.72 ; P<0.005)$, reaching the specific enzymatic activity of adult brain $(1.37 \pm 0.26 \mathrm{nmol} / \mathrm{mg}$ protein $/ \mathrm{hr})$.

Betaine-homocysteine methyltransferase specific activity was lower in fetal liver and brain $(1.82 \pm 0.21$ and $0.20 \pm 0.05 \mathrm{nmol} / \mathrm{mg}$ protein $/ \mathrm{hr})$ than in mature liver and brain $(7.78 \pm 1.89$ and $0.37 \pm 0.07 \mathrm{nmol} / \mathrm{mg}$ protein $/ \mathrm{hr})$. During the same period, there was a significant correlation of increasing enzymatic activity in fetal kidney with increasing crown-rump length $(r=0.80 ; P<0.005)$ toward the mean specific activity of mature kidney $(22.6 \pm 2.0 \mathrm{nmol} / \mathrm{mg}$ protein $/ \mathrm{hr})$.

Serine tetrahydrofolate 5,10-hydroxymethyltransferase specific activity showed no significant difference between fetal and mature liver and kidney; however, the fetal brain showed a significant correlation of decreasing specific activity of this enzyme with increasing crown-rump length $(r=-0.69 ; P<0.005)$.

The specific activities of betaine-homocysteine methyltransferase and serine-tetrahydrofolate 5,10-hydroxymethyltransferase in the liver of the neonate was not different from that in the mature liver. $\mathrm{iV}^{6}$-Methyltetrahydrofolate-homocysteine methyltransferase in neonatal liver attained a specific activity similar to that found in mature liver before cystathionase did.

Cystathionase in 2nd trimester human fetal kidney, in contrast to cystathionase in human fetal liver and brain, already has attained two-thirds of the mean specific activity of mature kidney.

\section{Speculation}

Although the measurements of these enzyme activities as assayed in vitro do not take into consideration substrate availability in vivo, the relative specific activities of these methyltransferases in human fetal liver and brain, considered together with the absence of cystathionase, suggests to us that perhaps, in these two organs, the transsulfuration pathway for the further metabolism of homocysteine is turned off in favor 
of the $\mathrm{N}^{6}$-methyltetrahydrofolate-Bi2remethylation pathway (Fig. 1). The latter pathway converts $7 \mathrm{~V}^{6}$-methyl tetrahydrofolate, the major monoglutamic folate in liver and serum [1], to tetrahydrofolate. The latter form of folate reacts with the $f 3$ carbon of serine, on serine-tetrahydrofolate 5,10 hydroxymethyltransferase, to form $N^{i} \bullet{ }^{10}$-methylenetetrahydrofolate, a 1-carbon precursor for the de novo synthesis of thymidylate, which is uniquely required for DNA but not for RNA. This suggests that the $/ 3$ carbon of serine is being shunted into DNA synthesis during periods of rapid cellular multiplication, rather than having the entire carbon skeleton accept the sulfur from homocysteine to form cysteine. The latter thus becomes an essential amino acid in human fetal liver and brain.

\section{Introduction}

In our previous studies of the transsulfuration pathway of methionine metabolism in the human fetus, cystathionase activity (EC. 4.2.1.15) was not measurable in the liver and brain $[10,19,25]$, and trace amounts of hepatic cystathionase, at most, were demonstrable by radiochemical perfusion studies [10] or immunochemically [14]. Since the transsulfuration pathway was shut off, with accumulation of cystathionine but without the accumulation of homocyst(e)ine $[10,19]$, it was of interest to examine the enzymatic activities of some methyltransferases involved in the metabolism of homocysteine (Fig. 1). The two major alternative pathways for remethylation to methionine

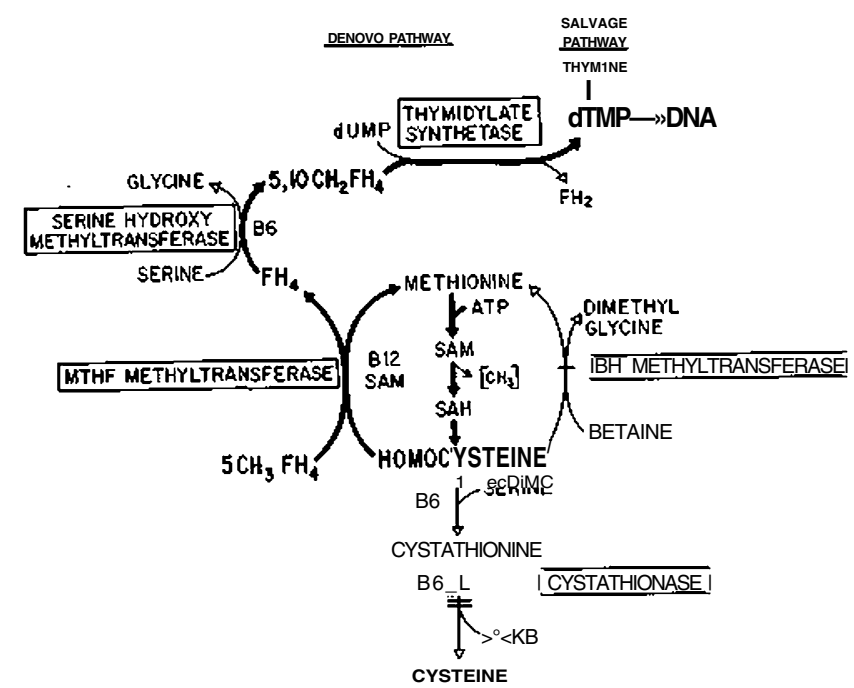

Fig. 1. Interrelationships of methionine metabolism, folate metabolism, and DNA synthesis in the human fetus. SAM: $S$ Adenosylmethionine; $S A H:$ S-adenosylhomocysteine; $d U M P$ : deoxyuridinemonophosphate; $d T M P$ : deoxythymidinemonophosphate; $c t-K B$ : ketobutyrate; $S C H^{\wedge} F H^{\wedge} \mathrm{JV}^{5}{ }^{5}{ }^{10}$-methyltetrahydrofolate; $\mathrm{FH}_{4}$ : tetrahydrofolate; $\mathrm{FH}_{., 2}$ : dihydrofolate; $5,10 \mathrm{CH}_{2} \mathrm{FH}_{t}$ : $N^{s}{ }_{-}{ }^{10}$-methylenetetrahydrofolate; $B^{\wedge}$ : vitamin $\mathrm{B}_{2} ; B_{6}$ : vitamin $\mathrm{B}_{\mathrm{e}}$; M.THF: methyltetrahydrofolate; $B H$ : betaine-homocysteine. were studied: $\mathrm{N}^{5}$-methyltetrahydrofolate (MTHF)homocysteine methyltransferase, the $\mathrm{B}_{12}$-linked enzyme which generates tetrahydrofolate (THF) from MTHF, and betaine-homocysteine $(\mathrm{BH})$ methyltransferase (EC. 2.1.2.5). L-Serine-tetrahydrofolate 5,10-hydroxymethyltransferase (STHF) (EC. 2.1.1.1) was also studied; it catalyzes the transfer of the $/ 3$ carbon of serine to THF, an important step in the de novo synthesis of thymidylate for incorporation into DNA, and has been reported to decrease in mouse brain during the neonatal period [2].

\section{Methods}

Included in this study were tissues from human fetuses (5.5-22.0 cm crown-rump length; approximately 2nd trimester) obtained at therapeutic abortion; livers from eight neonates, who died during the first 9 days of life and weighed from 680-4,000 $\mathrm{g}$ at birth; and tissues from mature humans with apparently normal organs at autopsy. Whole fetal brain was used, whereas the occipital lobe from mature brain was used. Control studies of rat liver, simulating conditions for postmortem autolysis, showed no significant changes in specific activity of the enzymes studied at 24 and $48 \mathrm{hr}$ after death.

The tissues were homogenized with 4 volumes of 0.03 $\mathrm{M}$ potassium phosphate buffer, $\mathrm{pH} 6.9$, and centrifuged at $15,000 \times \mathrm{g}$ for $30 \mathrm{~min}$. The supernate was removed, recentrifuged, and assayed for cystathionase [9], MTHF-methyltransferase [7, 26], BH-methyltransferase $[7,8,26]$, and STHF-methyltransferase [22]. In the latter assay, $0.33{ }^{\wedge}$ mole $3{ }^{14} \mathrm{C}$-L-serine was used instead of the 0.1 yumole stated in the published method [22, 26]. Preliminary experiments with rat liver had shown that extracts prepared as indicated had specific activities of all three enzymes greater than or equal to extracts prepared by the original methods.

The assays for MTHF-methyltransferase and 
STHF-methyltransferase are rate-limited with regard to one of their substrates, $2 \mathrm{~V}^{\mathrm{B}}$-methyltetrahydrofolate and serine, respectively. Therefore, control experiments were carried out in the monkey to be certain that the differences in specific activity were not due to differences in substrate concentration caused simply by different endogenous concentrations of these compounds. Monkey fetal organs showed the same relative specific activities of cystathionase and the methyltransferases as in the human fetus $[12,18]$. Because we could obtain ample liver from the fetus and its own mother, unknown and uncontrollable variables such as nutrition and postmortem interval would be eliminated. The differences reported below for the human fetus were found in the monkey fetus even when saturating amounts of each substrate were employed. Furthermore, the difference in activity in all three methyltransferases between fetal and mature tissues was not due to differences in $\mathrm{pH}$ optima.

\section{Results}

\section{Enzymatic Activities in Fetal Organs}

The most striking finding (Table I) is that the specific activity of MTHF-methyltransferase was considerably higher in fetal liver, brain, and kidney than in the corresponding mature tissue: liver was fourfold higher; kidney was an order of magnitude higher; and, during the period studied, there was a significant correlation of decreasing specific activity of this enzyme in brain with increasing crown-rump length $(\mathrm{r}=-0.72$; $P<0.005)$. This resulted in a threefold decrease to the specific activity of adult brain (Fig. 2).

In contrast, BH-methyltransferase was considerably lower in the same tissue; liver was fourfold lower; brain was twofold lower; and, during the period studied, there was a highly significant correlation of increasing specific activity in the kidney with increasing crown-rump length $(\mathrm{r}=0.80 ; P<0.005)$ toward, albeit not reaching the mean specific activity of mature kidney (Fig. 3).

There were no significant differences between the specific activities of STHF-methyltransferase in fetal and mature liver and kidney. The variance of the mean activities in these two tissues was great, somewhat more in the mature tissues than in the fetal tissues. The variance in mature brain was great as well, but fetal brain showed a significant correlation of decreasing specific activity of this enzyme with increasing crown-rump length $(r=-0.69, P<0.005)$ during the
Table I. Methyltransferase and cystathionase activities of human tissues

\begin{tabular}{|c|c|c|c|c|}
\hline & $\begin{array}{l}\text { MTHF-methyl- } \\
\text { transferase }\end{array}$ & $\begin{array}{l}\text { BH-methyl- } \\
\text { transferase }\end{array}$ & $\wedge " a h^{n}-s{ }^{\wedge}$ sf & Cystathionase \\
\hline $\begin{array}{c}\text { Mature liver } \\
\text { (17) }\end{array}$ & $\begin{array}{r}1.30 \\
\pm 0.16\end{array}$ & $\begin{array}{r}7.78 \\
\pm \quad 1.89\end{array}$ & $122 \pm 20$ & $126 \pm 12^{2}$ \\
\hline Fetal liver (31) & $\begin{array}{ll} & 4.70 \\
\pm & 0.203\end{array}$ & $\begin{array}{c}1.82 \\
\pm 0.21^{\prime}\end{array}$ & $99 \pm 9$ & 02 \\
\hline Neonatal liver & & & & \\
\hline $680 \mathrm{~g} ; 1$ day $^{1}$ & 1.71 & 7.96 & 32 & 43 \\
\hline 780 g; 1 day & 5.09 & 5.55 & 69 & 0 \\
\hline $\begin{array}{l}1,650 \mathrm{~g} ; 9 \\
\text { days }\end{array}$ & 1.60 & 6.24 & 237 & 86 \\
\hline $\begin{array}{l}\text { 1,780 g; } 3 \\
\text { days }\end{array}$ & 1.33 & 5.99 & 52 & 40 \\
\hline $\begin{array}{l}2,250 \mathrm{~g} ; 1 \\
\text { day }\end{array}$ & 2.12 & 9.03 & 93 & 17 \\
\hline $\begin{array}{l}2,600 \mathrm{~g} ; 6 \\
\text { days }\end{array}$ & 1.99 & 9.33 & 192 & 43 \\
\hline $\begin{array}{l}2,950 \mathrm{~g} ; 1 \\
\text { day }\end{array}$ & 1.78 & 11.04 & 134 & 37 \\
\hline $\begin{array}{l}4,000 \mathrm{~g} ; 4 \\
\text { days }\end{array}$ & 2.54 & 11.10 & 184 & 36 \\
\hline Mature brain & $\begin{array}{r}1.37 \\
+\quad 025\end{array}$ & 0.37 & $\begin{array}{r}7.38 \\
+\quad 4.33\end{array}$ & $33 \pm 6^{5}$ \\
\hline $\begin{array}{c}(6) \\
\text { Fetal brain } \\
(28)\end{array}$ & $\begin{array}{l} \pm 0.25 \\
(c f . \text { Fig. } 2)^{6}\end{array}$ & $\begin{array}{ll} \pm & 0.07 \\
& 0.20 \\
\pm & 0.053\end{array}$ & $\begin{array}{l} \pm 4.33 \\
\text { (cf. Fig. }{ }^{4} 6\end{array}$ & $0^{2}$ \\
\hline $\begin{array}{l}\text { Mature kidney } \\
\text { (6) }\end{array}$ & $\begin{array}{r}0.76 \\
\pm 0.18\end{array}$ & $\begin{array}{r}22.6 \\
\pm \quad 2.0\end{array}$ & $342 \pm 166$ & $32 \pm 5^{7}$ \\
\hline $\begin{array}{c}\text { Fetal kidney } \\
\text { (18) }\end{array}$ & $\begin{array}{ll} & 7.26 \\
\pm & 0.233\end{array}$ & (cf. Fig. 3)6 & $\begin{aligned} & 51.3 \\
+ & 5.7\end{aligned}$ & $21 \pm 5^{8}$ \\
\hline
\end{tabular}

${ }^{1}$ All values are nanomoles of product formed per milligram of soluble protein per hour $\pm \mathrm{SE}$. The numbers in parenthesis indicate numbers of individual samples. MTHF: Methyltetrahydrofolate; BH: betaine-homocysteine; STHF: L-serine-tetrahydrofolate 5,10-hydroxymethyltransferase.

${ }^{2}$ Values taken from References 10, 19.

${ }^{3} P<0.001$ by Student's unpaired $t$ test when compared with the mature tissues.

${ }^{4}$ Birth weight of infant; age at death.

${ }^{5}$ Seven samples; includes one additional value for occipital lobe previously published [10, 19].

${ }^{6}$ Significant correlation.

${ }^{7}$ Eight samples; includes two additional values for mature kidney previously published, [20].

${ }^{8}$ Six samples; $0.01<P<0.05$ by Student's unpaired $t$ test when compared with mature kidney.

period studied (Fig. 4). This resulted in a threefold decrease to the specific activity of mature brain by the end of this period.

Human fetal kidney had not previously been examined for specific activity of cystathionase, but 3rd trimester fetal monkey kidney showed a mean specific activity of cystathionase equal to or greater than that of mature monkey kidney $[12,18]$. Furthermore, human fetal kidney resembled human fetal liver and brain in 


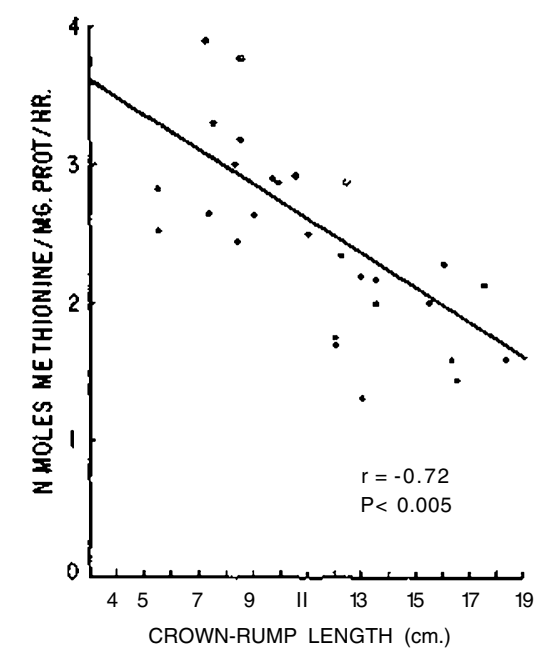

Fig. 2. $\mathrm{iV}^{\mathrm{B}}$-methyHetrahydrofolate-homocysteine methyltransferase activity in human fetal brain. PROT: protein.

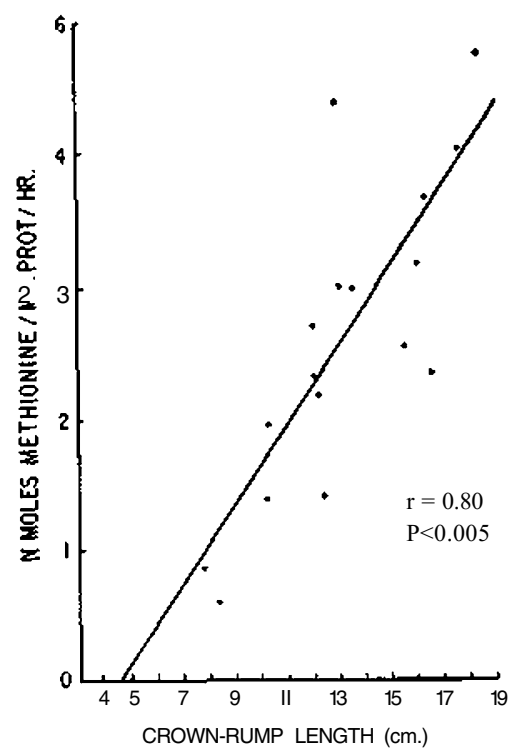

Fig. 3. Betaine-homocysteine methyltransferase activity in human fetal kidney. PROT: protein.

that the mean specific activity of fetal kidney MTHFmethyltransferase was higher than that of mature kidney (Table I). It differed from fetal liver and brain in that the specific activity of BH-methyltransferase was already increasing toward that of mature kidney (Fig. 3 ). It is of considerable interest, therefore, that 2 nd trimester human fetal kidney also differs from 2nd trimester human fetal liver and brain in having a mean specific activity of cystathionase that is two-thirds that of mature kidney (Table I).

\section{Enzymatic Activities in Neonatal Liver}

Our previous work indicated that the emergence of cystathionase was a postnatal phenomenon [10, 19]. Thus, liver extracts from newly born infants were examined for the specific activity of these three methyltransferases, as well as for cystathionase (Table I). Liver extracts from all of the neonates, but one, had easily measurable activities of cystathionase, although only one of these approached the mean activity found in mature liver. The specific activities of MTHF-methyltransferase in all of the neonatal liver extracts, but one, ranged from twofold higher to the mean activity of mature liver. The liver extract with the highest specific activity of cystathionase had the lowest specific activity of MTHF-methyltransferase. The one neonatal liver extract that had no measurable cystathionase activity had the highest specific activity of MTHFmethyltransferase, a specific activity similar to that found in fetal liver.

Extracts of liver from all of the neonates had specific activities of BH-methyltransferase which were in the range of those of mature liver. Extracts of liver from only two infants had specific activities of STHF-methyltransferase which were low. Thus, it appears that adult values of activity of BH- and STHF-methyltransferases are attained before MTHF-methyltransferase activity in human liver, most likely during the last trimester of gestation, but possibly during the 1st postnatal day. The MTHF-methyltransferase appears to attain adult values of activity in the immediate postnatal period, but before cystathionase. These results do not eliminate the possibility that adult values for the

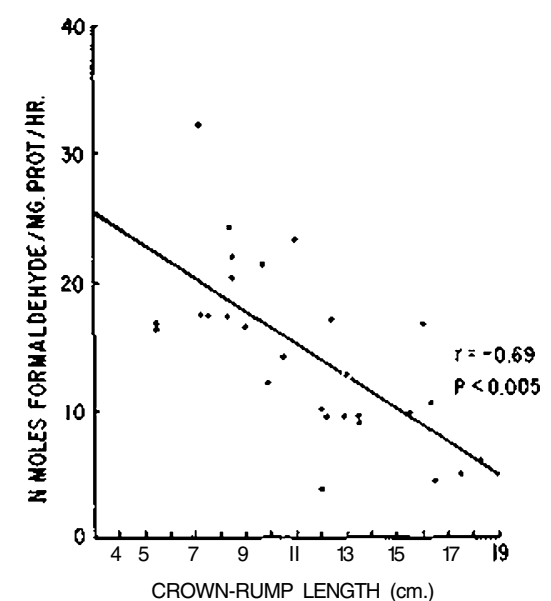

Fig. 4. Serine-tetrahydrofolate 5,10-hydroxymethyltransferase activity in human fetal brain. PROT: protein. 
specific activity of MTHF-methyltransferase may be attained during the 3rd trimester of gestation.

\section{Discussion}

The fact that homocyst(e)ine does not accumulate in fetal tissues in the absence of cystathionase is one of the reasons we investigated the related methyltransferases. There are four enzymes competing for homocysteine (Fig. 1): cystathionine synthase, MTHF-methyltransferase, BH-methyltransferase, and 5-adenosylhomocysteine hydrolase (EC. 3.3.1.1). The last is readily reversible, although the equilibrium is in favor of synthesis of S-adenosylhomocysteine [4]. This is probably one reason why homocysteine is not measurable in tissues, even in liver extracts from two patients with cystathionine synthase deficiency [12]. The $K_{m}$ for cystathionine synthase is $12 \times 10 \sim^{3}$, whereas that of MTHF-methyltransferase is $6 \times 10^{\mathrm{B}}$, and that of BHmethyltransferase is $4 \times 10 \sim^{5}$ [5]. Thus, the methyltransferases would be likely to compete for the limited free homocysteine against cystathionine synthase rather effectively on the basis of their low $K_{m}$ values, and S-adenosylhomocysteine hydrolase would be readily pulled in the direction of cleavage rather than of synthesis.

Consideration of relative $K_{m}$ values and competition for homocysteine would offer an explanation of why homocysteine does not accumulate when cystathionase is absent. It alone does not provide explanation of our earlier striking finding that there is less cystathionine in fetal human brain than in mature human brain $[10$, 19], despite the fact that cystathionase, the first enzyme for its further degradation, is virtually absent from fetal brain. A lower concentration of cystathionase in fetal brain than in adult brain has also been reported for Rhesus monkey [18]. Cystathionine synthase has been considered essentially unidirectional, and with cystathionase absent one might expect more, rather than less, cystathionine in fetal brain. However, at least one assay for cystathionine synthase involves the use of cystathionine as substrate and measures the production of homocysteine trapped as its 5,5'-dithiobis[(1-nitrobenzoic)]acid derivative [3]. Thus, it is reversible, at least when homocysteine is constantly removed. Under the circumstances in which cystathionase is absent, cystathionine synthase is at least partially reversible, and homocysteine is constantly removed, the concentration of cystathionine in fetal brain would be less than in adult brain; i.e., the concentrations of cystathionine in brain is a function of the activity of
MTHF-methyltransferase, as well as of the activity of cystathionase.

The control experiments with increasing concentrations of substrate which were carried out in extracts of liver from monkey established that the differences in specific activity of MTHF-methyltransferase between fetal and maternal liver were not spurious differences in activity due to the use of an enzymatic assay ratelimited with regard to substrate. They also showed that there was a difference in the concentration of substrate required for saturation [21]. The MTHFmethyltransferase from fetal liver required more MTHF for full saturation; however, at any particular concentration of MTHF, the fetal extract showed a higher specific activity. This interesting difference will be explored further on purified extracts.

Since the specific activity of BH methyltransferase is lower in fetal than in mature tissues, the enzymatic potential is thereby provided for serine to be shunted in the direction of the folate- $\mathrm{B}_{12}$ remethylation pathway with eventual incorporation of its $f 3$ carbon into thymidylate and production of glycine by the residuum. Further support for this hypothesis comes from fragmentary evidence that two other enzymes important in the de novo synthesis of thymidylate, dihydrofolate reductase [15] and thymidylate synthase [16], are higher in fetal liver than in mature liver. However, proof of this hypothesis must await direct evidence of the metabolic flux.

As a corollary, when cystathionase activity appears, the entire carbon skeleton of serine could be converted to cysteine. Cystathionine is cleaved to cysteine and a-ketobutyrate. Since the latter is readily metabolized, cystathionase is pulled in the direction of cysteine. Furthermore, cystathionase is reversed only with great difficulty; it requires amounts of homoserine likely to be available only under conditions of homoserine loading, and it will not reverse at all with «-ketobutyrate as cosubstrate with cysteine [11].

In the fetal kidney there is easily measurable activity of cystathionase, and it is possible that during fetal development, the kidney partly subserves the transsulfuration function of the liver and brain in postnatal life. However, even in the adult, the activity of cystathionase in kidney reaches only one-quarter that in liver (Table I). Studies with ${ }^{35} \mathrm{~S}$-methionine in the pregnant Rhesus monkey [18] do not lend support to the idea that the kidney can subserve the transsulfuration function of the liver in the fetus. It is of interest that the kidney, when mature, is an organ which incor- 
porates relatively large amounts of ${ }^{35} \mathrm{~S}$ from ${ }^{35} \mathrm{~S}$-methionine and ${ }^{3 \mathrm{~s}} \mathrm{~S}$-cystine into cystine $[17,18]$.

Comparison of these studies in the human fetus with our studies in the monkey fetus [18], with similar studies in the immature rat [7], and with studies in the immature mouse [2] further highlights the differences between species and the importance of studying the tissues of the previable human fetus. Some differences between species may be due to variations in maturity at birth: STHF-methyltransferase decreases during the postnatal period in the brain of the mouse [2] and during the 2nd trimester in the brain of the human fetus (Fig. 4), which would be corresponding periods of rapid growth in each [6]. The specific activity of MTHF-methyltransferase in rat liver decreases gradually during the postnatal period [7], whereas most of the human neonatal livers studied by us had already attained the specific activity found in adult liver (Table I). Other differences may be due to intrinsic variations between species: BH-methyltransferase in the liver of the rat decreases slightly as the animal matures [7], whereas there is a striking increase in the human (Table I). There is considerably more $\mathrm{BH}-$ methyltransferase in the mature human kidney than in the mature human liver (Table I), which is in striking contrast to the rat, which has very little activity in the kidney [7, 23].

The high activities of the $\mathrm{B}_{12}$-linked MTHF methyltransferase in human fetal brain suggests that, in the inherited deficiency of MTHF-methyltransferase because of failure of activation of vitamin $B_{12}$ to its coenzyme form [12], severe impairment of brain development may well occur early because of a slow rate of synthesis of DNA during periods of rapid neuronal multiplication. Indeed, one wonders how this defect is compatible with survival, unless there is an MTHFmethyltransferase pathway in human fetal brain which is not $\mathrm{B}_{12}$ dependent, such as may exist in mitochondria from rat liver [24]. Alternatively, despite the fact that MTHF is the major folate in maternal blood, there may be sufficient placental transfer of THF and its other derivatives from the mother to circumvent the block in synthesis of THF by the affected fetus until after birth.

\section{Summary}

Activity of $2 V^{5}$-methyltetrahydrofolate-homocysteine methyltransferase was higher in liver, brain, and kidney of the human fetus (2nd trimester) than in the same organs from the mature human. The reverse was true for the activity of betaine-homocysteine methyltransferase. Activity of serine tetrahydrofolate 5,10-hydroxymethyltransferase in liver and kidney at this period of fetal development was not different from that in the mature human; however, this activity was higher in fetal brain and decreased to the mean activity in the brain of the mature human during the 2nd trimester. These methyltransferases appear to reach mature activity by the early neonatal period and somewhat earlier than cystathionase.

The development of cystathionase in human fetal kidney is different from its development in human fetal liver and brain in that it is not absent and has attained two-thirds of the mean specific activity found in adult kidney.

\section{References and Notes}

1. BLAKELEY, R. L.: The Biochemistry of Folic Acid and Related Pteridines. (American Elsevier, New York, 1969).

2. BRIDGERS, W. F.: Serine transhydroxymethylase in developing mouse brain. J. Neurochem., 15: 1325 (1968).

3. BROWN, F. C, AND GORDON, P. H.: Cystathionine synthase from rat liver: partial purification and properties. Can. J. Biochem., 49: 484 (1971).

4. DELA HABA, G., AND CANTONI, G. L.: The enzymatic synthesis of S-adenosyl L-homocysteine from adenosine and homocysteine. J. Biol. Chem., 239: 2545 (1959).

5. FINKELSTEIN, J. D.: Methionine metabolism in mammals. In: N. A. J. Carson and D. N. Raine: Inherited Disorders of Sulphur Metabolism. (Churchill Livingstone, London, 1971).

6. DOBBING, J.: Undernutrition and the developing brain. In: A. Lajtha: Handbook of Neurochemistry, Vol. 6 Chapt. 9. (Plenum Press, New York, 1971).

7. FINKELSTEIN, J. D., KYLE, W. E., AND HARRIS, B. J.: Methionine metabolism in mammals: Regulation of homocysteine methyltransferases in rat tissue. Arch. Biochem. Biophys., 146: 84 (1971).

8. FINKELSTEIN, J. D., AND MUDD, S. H.: Transulfuration in mammals. The methionine-sparing effect of cystine. J. Biol. Chem., 242: 873 (1967).

9. GAULL, G. E., RASSIN, D. K., AND STURMAN, J. A.: Enzymatic and metabolic studies of homocystinuria: Effects of pyridoxine. Neuropadiatrie, 1: 99 (1969).

10. GAULl, G. E., STURMAN, J. A., AND RAIHA, N. C. R.: Development of mammalian sulfur metabolism: Absence of cystathionase in human fetal tissues, Pediat. Res., 6: 538 (1972).

11. GAULL, G. E., WADA, Y., SCHNEIDMAN, K., RASSIN, D. K., TALLAN, H. H., AND STURMAN, J. A.: Homocystinuria: Observations on the biosynthesis of cystathionine and homolanthionine. Pediat. Res., 5: 265 (1971).

12. GAULL, G. E., AND STURMAN, J. A.: Unpublished observations.

13. MUDD, S. H., LEVY, H. L., AND MORROW, G.: Deranged $B_{12}$ metabolism: Effects on sulfur amino acid metabolism. Biochem. Med., 4: 193 (1970).

14. PASCAL, T. A., Gillam, B. M., AND GAUll, G. E.: Cystathionase: Immunochemical evidence for absence from human fetal liver. Pediat. Res., 6: 773 (1972).

15. ROBERTS, D., AND HALL, T. C: Studies on folic reductase. II. 
Enzyme activity of embryonic organs of the chicken, rat and human. Cancer Res., 24: 989 (1964).

16. MALEY, F., AND MALEY, G. F.: Nucleotide interconversions. IV. Activities of deoxycytidylate deaminase and thymidylate synthetase in normal rat liver and hepatomas. Cancer Res., 21: 1421 (1961).

17. STURMAN, J. A., COHEN, P. A., AND GAULl, G. E.: Metabolism of $\mathrm{L}-^{\wedge} \mathrm{S}-$-methionine in vitamin $\mathrm{B}_{6}$ deficiency: Obervations on cystathioninuria. Biochem. Med., 3: 510 (1970).

18. STURMAN, J. A., NIEMANN, W. H., AND GAULL, G. E.: Metabolism of ${ }^{\wedge} \mathrm{S}$-methionine and ${ }^{\wedge} \mathrm{S}$-cystine in the pregnant Rhesus monkey. Biol. Neonate (in press).

19. STURMAN, J. A., GAULl, G., AND RÄIHÄ, N. C. R.: Absence of cystathionase in human fetal liver: Is cystine essential? Science, 169: 74 (1970).

20. STURMAN, J. A., RASSIN, D. K., AND GAULL, G. E.: Distribution of transsulfuration enzymes in various organs and species. Int. J. Biochem., 1: 251 (1970).

21. TALLAN, H. H., AND GAULL, G. E.: Unpublished observations.

22. TAYLOR, R. T., AND WEISSBACH, H.: Radioactive assay for serine transhydroxymethylase. Anal. Biochem., 13: 80 (1965).

23. VON BERG, W., AND STURMAN, J. A.: Unpublished observations.

24. WANG, F. K., KOCH, J., AND STOKSTAD, E. L. R.: Folate coenzyme pattern, folate-linked enzymes and methionine biosynthesis in rat liver mitochondria. Biochem. Z., 346: 458 (1967).
25. Cystathionase has been used rather than L-homoserine hydrolyase (deaminating) EC. 4.2.1.15, since it is the transsulfuration function we are studying.

26. 5-(Methyl- $\left.{ }^{\mathrm{u}} \mathrm{C}\right)$-tetrahydrofolate and $3-{ }^{\mathrm{M}} \mathrm{C}-\mathrm{L}$-serine were obtained from Amersham/Searle Corporation, Arlington Heights, 111.

27. (Methyl-"C)-betaine was obtained from New England Nuclear, Boston, Mass.

28. The authors thank Miss Rautikallio and the staff of the Department of Obstetrics and Gynecology of the Central University Hospital, Helsinki, for help and cooperation, Dr. Harris Tallan for helpful discussion, and Miss Karmella Schneidman for expert assistance with enzyme assays.

29. The expenses of these studies were shared by New York State Department of Mental Hygiene, Lalor Foundation, Association for the Aid to Crippled Children, and Clinical Genetics Center Grant no. GM-19443, United States Public Health Service. Dr. von Berg was the recipient of a generous grant from the B. Braun Foundation, Melsungen, West Germany.

30. Requests for reprints should be addressed to: GERALD E. GAULL, M.D., Department of Pediatric Research, Institute for Basic Research in Mental Retardation, Staten Island, N.Y. 10314 (USA)

31. Accepted for publication December 27, 1972. 